\title{
Altered mRNA expression levels of the major components of sphingolipid metabolism, ceramide synthases and their clinical implication in colorectal cancer
}

\author{
SUNG WON JANG ${ }^{1 *}$, WOO-JAE PARK ${ }^{2 *}$, HYEONJI MIN $^{3}$, TAEG KYU KWON $^{3,4}$, SEONG KYU BAEK $^{5}$, \\ ILSEON HWANG ${ }^{6}$, SHIN KIM ${ }^{3,4}$ and JONG-WOOK PARK ${ }^{3,4}$ \\ ${ }^{1}$ Department of Emergency Medicine, Dongsan Medical Center, Keimyung University, \\ Daegu 41931; ${ }^{2}$ Department of Biochemistry, College of Medicine, Gachon University, Incheon 21999; \\ ${ }^{3}$ Department of Immunology, School of Medicine and ${ }^{4}$ Institute of Medical Science, Keimyung University, \\ Daegu 42601; ${ }^{5}$ Department of Surgery, Dongsan Medical Center, Keimyung University, Daegu 41931; \\ ${ }^{6}$ Department of Pathology, School of Medicine, Keimyung University, Daegu 42601, Republic of Korea
}

Received January 11, 2018; Accepted September 3, 2018

DOI: $10.3892 /$ or.2018.6712

\begin{abstract}
Ceramide synthases (CerSs) synthesize various ceramides of different acyl chain lengths and serve important roles in the proliferation and death of cancer cells by regulating sphingolipid metabolism-related signaling pathways. The present study investigated the mRNA expression levels of various CerS genes using mRNA expression data from six independent colorectal cancer (CRC) cohorts and a Korean CRC dataset. Expression levels of CERS2, CERS5 and CERS6 mRNA were significantly increased in the majority of the studied groups. However, CERS4 expression was only significantly altered in two groups. Additionally, a positive correlation was observed between altered CERS 4 and
\end{abstract}

Correspondence to: Professor Shin Kim or Professor Jong-Wook Park, Department of Immunology, School of Medicine, Keimyung University, 1,095 Dalgubeoldaero, Daegu 42601, Republic of Korea E-mail: god98005@dsmc.or.kr

E-mail: j303nih@dsmc.or.kr

${ }^{*}$ Contributed equally

Abbreviations: CRC, colorectal cancer; CerS, ceramide synthase; TCGA-COADREAD, The Cancer Genome Atlas Colon and Rectal Cancer; qPCR, quantitative polymerase chain reaction; NST, non-neoplastic surrounding colon tissues; LPAR1, lysophosphatidic acid receptor 1; NAAA, N-acylethanolamine acid amidase; SPHK1, sphingosine kinase 1; HPGD, 15-hydroxyprostaglandin dehydrogenase; SMPD1, sphingomyelin phosphodiesterase 1; SMPDL3A, sphingomyelin phosphodiesterase acid-like 3A; UGGT2, UDP-glucose glycoprotein glucosyltransferase 2; HA-CERS2, HA-tagged form of CERS2; HA-CERS6, HA-tagged form of CERS6

Key words: ceramide synthase, colorectal cancer, The Cancer Genome Atlas, sphingolipid metabolism, cBioPortal
CERS5 mRNA levels in The Cancer Genome Atlas Colon and Rectal Cancer dataset. Notably, CERS2 and CERS4, as well as CERS5 and CERS6 levels, were positively correlated with each other in Korean patients with CRC. However, the mRNA expression levels of these four CerS genes were not associated with any clinicopathological characteristics in Korean patients with CRC. Finally, overexpressing CERS 2 or CERS6 inhibited the in vitro viability of various CRC cells. Taken together, these findings indicated that CERS2, CERS4, CERS5, and CERS6 are significantly dysregulated in CRC, suggesting they may serve important roles in the pathophysiology of this malignancy.

\section{Introduction}

Colorectal cancer (CRC) is a malignancy derived from the colorectal epithelium and is the third most commonly diagnosed cancer type worldwide (1). Although the mortality rates of $\mathrm{CRC}$ have been decreasing due to screening, reduced risk factor prevalence and/or improved therapies $(2,3), \mathrm{CRC}$ remains a global health burden in terms of morbidity and mortality, with $\sim 700,000$ estimated mortalities annually (1). It has been reported that the complicated and complex pathogenetic mechanisms of $\mathrm{CRC}$ involve genomic rearrangements, chromatin remodeling, genetic mutations and epigenetic changes $(4,5)$.

The sphingolipid rheostat is a proposed concept that may regulate cell fate decisions (6). The two major components of the sphingolipid rheostat are ceramide and sphinogosine-1 phosphate, which are interconvertible sphingolipid metabolites that regulate cell growth and survival by modulating sphingolipid rheostat-related signaling $(6,7)$. Ceramide has tumor suppressive anticancer properties, including potentiating signaling networks that drive apoptosis, autophagy and cell cycle arrest (8). Ceramide synthases (CerSs) are integral membrane proteins of the endoplasmic reticulum that synthesize ceramides of different acyl chain lengths. To date, six CerS families have been identified in mammals (9). Dysregulation 
of CerS activity has been reported to be associated with tumor cell invasion (10), proliferation (11), apoptosis (12) and epithelial-mesenchymal transition (13), as well as with the prognosis of patients with cancer (14). For example, in head and neck squamous cell carcinoma, downregulation of CERSI leads to apoptotic resistance (15), while CERS1 overexpression enhances growth-inhibitory effects (16). Additionally, CERS2, CERS4 and CERS6 mRNA expression levels are increased in breast cancer (17), and the upregulation of CERS4 and CERS6 leads to reduced cell proliferation and the induction of apoptosis (18). Given these results and the association of altered CerS expression with malignant transformation, the present study aimed to characterize the mRNA expression of various CerS genes in CRC and non-neoplastic adjacent tissues (NST).

The present study investigated the mRNA expression levels of various CerS genes using mRNA expression data from six independent CRC cohorts and a Korean CRC dataset. Furthermore, the clinical significance of altered CerS genes expression was evaluated in the Korean CRC dataset.

\section{Materials and methods}

Gene expression databases and cluster analysis. Gene expression RNAseq dataset (Level 3) and clinical data for The Cancer Genome Atlas Colon and Rectal Cancer (TCGA-COADREAD) cohort (19) were downloaded from the UCSC Xena (https://xena.ucsc.edu). CRC gene expression microarray data used in this study were downloaded from the publicly available GEO databases (http://www.ncbi.nlm.nih. gov/geo/): GSE21815 (20), GSE44076 (21), GSE44861 (22), GSE41258 (23) and GSE33113 (24). The GEO datasets used in this study include 562 CRC tissues and 222 NST from respective same patient groups. The downloaded raw data of GEO databases were normalized at the transcript and gene level using the Robust Multichip Average method (25). Cluster analysis was performed using Cluster 3.0 to classify the samples into statistically similar groups, and the resulting heatmaps were visualized in TreeView 1.6 (www.eisenlab.org/eisen). The four CerS genes present in the TCGA COADREAD, GSE44076 and GSE44861 cohorts were LASS2, LASS4, LASS5 and LASS6. The present study meets the publication guidelines provided by TCGA.

Patients and tissues. A total of 59 patients (mean age, 64.83 \pm 9.48 ; age range, 38-83; 34 males and 25 females) diagnosed with CRC were included in the present study. CRC and NSTs were obtained from patients undergoing surgery in Keimyung University Dongsan Medical Center (Daegu, Korea) between April 2008 and January 2010. Enrolled patients with CRC were classified according to the AJCC Tumor-Node Metastasis (TNM) staging criteria (26). Tissue samples were immediately frozen in liquid nitrogen and stored at $-196^{\circ} \mathrm{C}$ until RNA isolation. Tissue samples were provided by Keimyung Human Bio-Resource Bank (Daegu, Korea). Written informed consent was obtained from each study participant and the protocols were approved by the Institutional Review Board of Keimyung University Dongsan Medical Center (approval no. 2015-11-059-001).

RNA isolation and reverse transcription-quantitative polymerase chain reaction ( $R T-q P C R)$. Total cellular RNA was
Table I. Primer sequences used in quantitative polymerase chain reaction.

\begin{tabular}{ll}
\hline Primer & \multicolumn{1}{c}{ Sequence } \\
\hline CERS2 sense & 5'-ATCGTCTTCGCCATTGTTTT-3' \\
CERS2 antisense & 5'-GGCAGGATAGAGCTCCAGTG-3' \\
CERS4 sense & 5'-GGAGGCCTGTAAGATGGTCA-3' \\
CERS4 antisense & 5'-GAGGACCAGTCGGGTGTAGA-3' \\
CERS5 sense & 5'-TGGAATTGGCCTTCTATTGG-3' \\
CERS5 antisense & 5'-CAATGGTGACCAAGTGATGC-3' \\
CERS6 sense & 5'-TGCCATTCTGGAAAAGGTCT-3' \\
CERS6 antisense & 5'-ATGCTTCGAACATCCCAGTC-3' \\
$\beta$-actin sense & 5'-CAGCCATGTACGTTGCTATCCAGG-3' \\
$\beta$-actin antisense & 5'-AGGTCCAGACGCAGGATGGCATG-3'
\end{tabular}

CERS, ceramide synthase mRNA.

extracted from tissues using TRIzol reagent (Invitrogen; Thermo Fisher Scientific, Inc., Waltham, MA, USA). RNA was quantified using NanoDrop 1000 (Thermo Fisher Scientific, Inc.). Each cDNA was synthesized from $2 \mu \mathrm{g}$ total RNA using MMLV reverse transcriptase (Promega Corporation, Madison, WI, USA), according to the manufacturer's protocol. qPCR was performed on the LightCycler ${ }^{\circledR} 480$ Real-Time PCR system (Roche Diagnostics GmbH, Mannheim, Germany) using the specific primer pairs presented in Table I and SYBR-Green Premix (Toyobo Life Science, Osaka, Japan). The qPCR was performed using the following thermocycling conditions: $95^{\circ} \mathrm{C}$ for $10 \mathrm{~min}$; followed by 45 cycles of $95^{\circ} \mathrm{C}$ for $10 \mathrm{sec}, 60^{\circ} \mathrm{C}$ for $10 \mathrm{sec}$, and $72^{\circ} \mathrm{C}$ for $12 \mathrm{sec}$. Melting curve was analyzed to determine primer specificity. b-actin was used as a housekeeping gene for normalization, and a no-template sample was used as a negative control. qPCR data were analyzed using the $2^{-\Delta \Delta \mathrm{Cq}}$ method (27). Each experiment was performed three times.

Statistical analysis. Statistical analysis was performed using SPSS 22.0 (IBM Corp., Armonk, NY, USA). The cell viability data were analyzed using one-way analysis of variance and the Student-Newman-Keuls post hoc test. Differences between the groups were analyzed statistically using Student's t-test or Mann Whitney U test. The co-expression of the mRNAs of various CerS genes in TCGA-COADREAD cohort were searched using cBioPortal (http://cbioportal.org) (28). The association between inter-individual mRNA expression levels of CerS genes in Korean patients with CRC was assessed using Pearson's correlation coefficient analysis for continuous variables. Clinicopathological associations with the mRNA expression levels of various CerS genes in Korean CRC were analyzed using the Linear by linear association, the Pearson's Chi-square test and the Fisher's exact test for categorical variables. The mean value was used as the cut-off value (low and high) for categorical variables. $\mathrm{P}<0.05$ was considered to indicate a statistically significant difference.

Transient transfection. Various human colorectal adenocarcinoma cell lines, HCT116, HT29, SW403 and SW480 cells, 

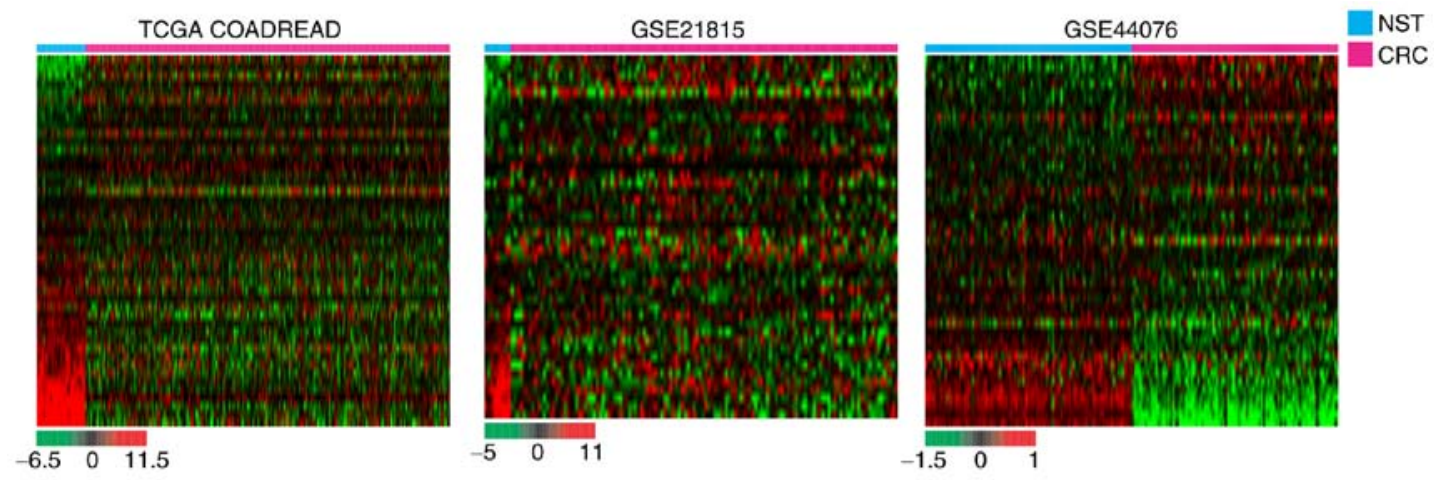

GSE44861
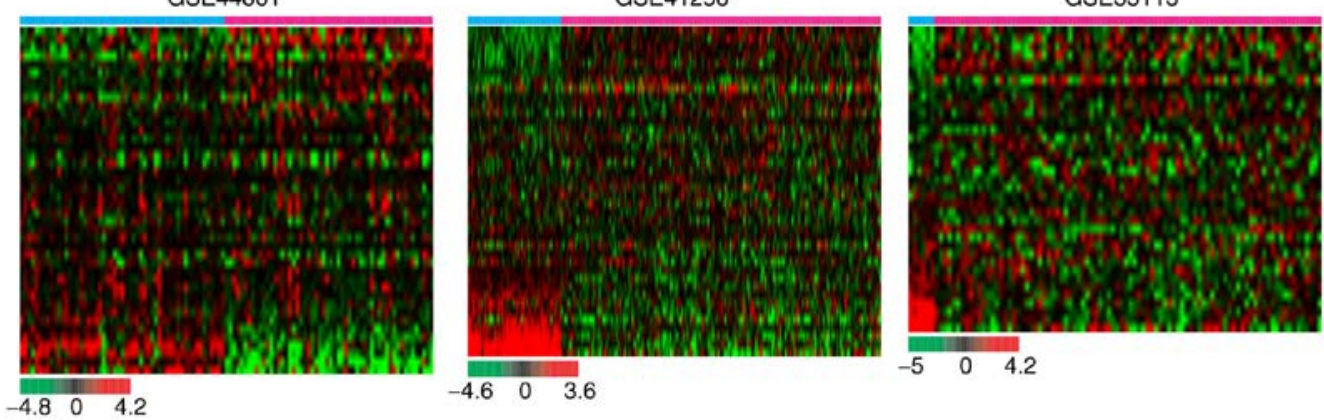

Figure 1. Heat-map showing the sphingolipid metabolism-related genes in CRC tissues compared with NST of 6 independent CRC cohorts. The data are presented in matrix format in which rows represent individual genes and columns represent each tissue. Each cell in the matrix represents the expression level of a gene feature in an individual tissue. Expression levels have been standardized (centered and scaled) within columns for visualization. The red and green colors in cells reflect relative high and low expression levels, respectively, as indicated by the scale bar. Images were obtained by re-analysis of the raw data of respective cohort. CRC, colorectal cancer; NST, non-neoplastic surrounding colon tissues; TCGA-COADREAD, The Cancer Genome Atlas Colon and Rectal Cancer.

were plated onto 6-well plates at a density $7 \times 10^{5}$ cells/well and cultured overnight. pcDNA3.1-empty vector was used for plasmid constructs, including HA-tagged form of CERS2 (HA-CERS2) and HA-tagged form of CERS6 (HA-CERS6) constructs. All plasmids, including pcDNA3.1-empty vector, HA-CERS2 and HA-CERS6 were provided by Professor Anthony H. Futerman (Weizmann Institute of Science, Rehovot, Israel). The CRC cells were transfected with pcDNA3.1-empty vector, $2 \mu \mathrm{g}$ HA-CERS2 and HA-CERS6 plasmid in 6-well plates using Lipofectamine reagent (Invitrogen; Thermo Fisher Scientific, Inc.), according to the manufacturer's protocol. At $24 \mathrm{~h}$ after plasmid transfection, the subsequent experiments were conducted.

Western blot analysis. The transient transfected CRC cells were collected and washed twice with cold PBS, and cell pellets were prepared by suspending in modified radioimmunoprecipitation assay buffer (50 mM Tris- $\mathrm{HCl} \mathrm{pH} 7.4,1 \% \mathrm{NP}-40,0.25 \%$ Na-deoxycholate, $150 \mathrm{mM} \mathrm{NaCl}, 1 \mathrm{mM} \mathrm{Na}_{3} \mathrm{VO}_{4}$ and $1 \mathrm{mMNaF}$ ) containing protease inhibitors $(100 \mu \mathrm{M}$ phenylmethylsulfonyl fluoride, $10 \mu \mathrm{g} / \mathrm{ml}$ leupeptin, $10 \mu \mathrm{g} / \mathrm{ml}$ pepstatin and $2 \mathrm{mM}$ EDTA). The lysates were centrifuged at $10,000 \mathrm{x} g$ for $10 \mathrm{~min}$ at $4^{\circ} \mathrm{C}$, and the supernatant fractions were collected. The total protein concentration was measured using Micro $\mathrm{BCA}^{\mathrm{TM}}$ Protein assay kit (Thermo Fisher Scientific, Inc.), according to the manufacturer's protocol. Cellular proteins $(60 \mathrm{mg})$ were mixed with protein $5 \mathrm{X}$ sample buffer (Elpis Biotech., Inc., Daejeon, Korea) and heated at $95^{\circ} \mathrm{C}$ for $5 \mathrm{~min}$. The proteins were separated by $10 \%$ SDS-PAGE and then electrotransferred to Immobilon-P membranes (EMD Millipore, Billerica, MA, USA). The membranes were then blocked at room temperature with 5\% skimmed dried milk in PBS/0.1\% Tween-20 for $1 \mathrm{~h}$, and incubated overnight at $4^{\circ} \mathrm{C}$ with anti-HA (1:2,000; mouse monoclonal; cat. no. SAB1411737) and anti- $\beta$-actin $(1: 2,000$; mouse monoclonal; cat. no. A5441; both Sigma-Aldrich; Merck KGaA, Darmstadt, Germany). The membranes were then washed six times with PBS/0.1\% Tween-20 (30 min each) and incubated with the corresponding secondary antibodies (horseradish peroxidase-conjugated, horse antibodies to mouse IgG; 1:2,000; cat. no. 7076; Cell Signaling Technology, Inc.) for $1 \mathrm{~h}$ at room temperature. Following washing six times in PBS/0.1\% Tween-20, the specific protein bands were detected using an enhanced chemiluminescence western blotting kit (EMD Millipore), according to the manufacturer's protocol.

\section{Results}

Altered expression levels of sphingolipid metabolism-related genes in six independent CRC cohorts. To investigate whether the sphingolipid metabolism-related genes (29) are dysregulated in CRC tissues, the present study re-analyzed the raw data of six independent CRC cohorts. To begin with, the cancer gene expression RNAseq datasets of 380 CRC patients were taken from the TCGA-COADREAD cohort through UCSC Xena. Next, CRC gene expression microarray data were downloaded from the publicly available Gene Expression Omnibus databases. The CRC gene expression microarrays, GSE21815, GSE33113, GSE41258, GSE44076 and GSE44861, were analyzed for potential transcriptome changes. Hierarchical clustering revealed that various sphingolipid metabolism-related genes were dysregulated in carcinomatous tissues compared with NST of patients 

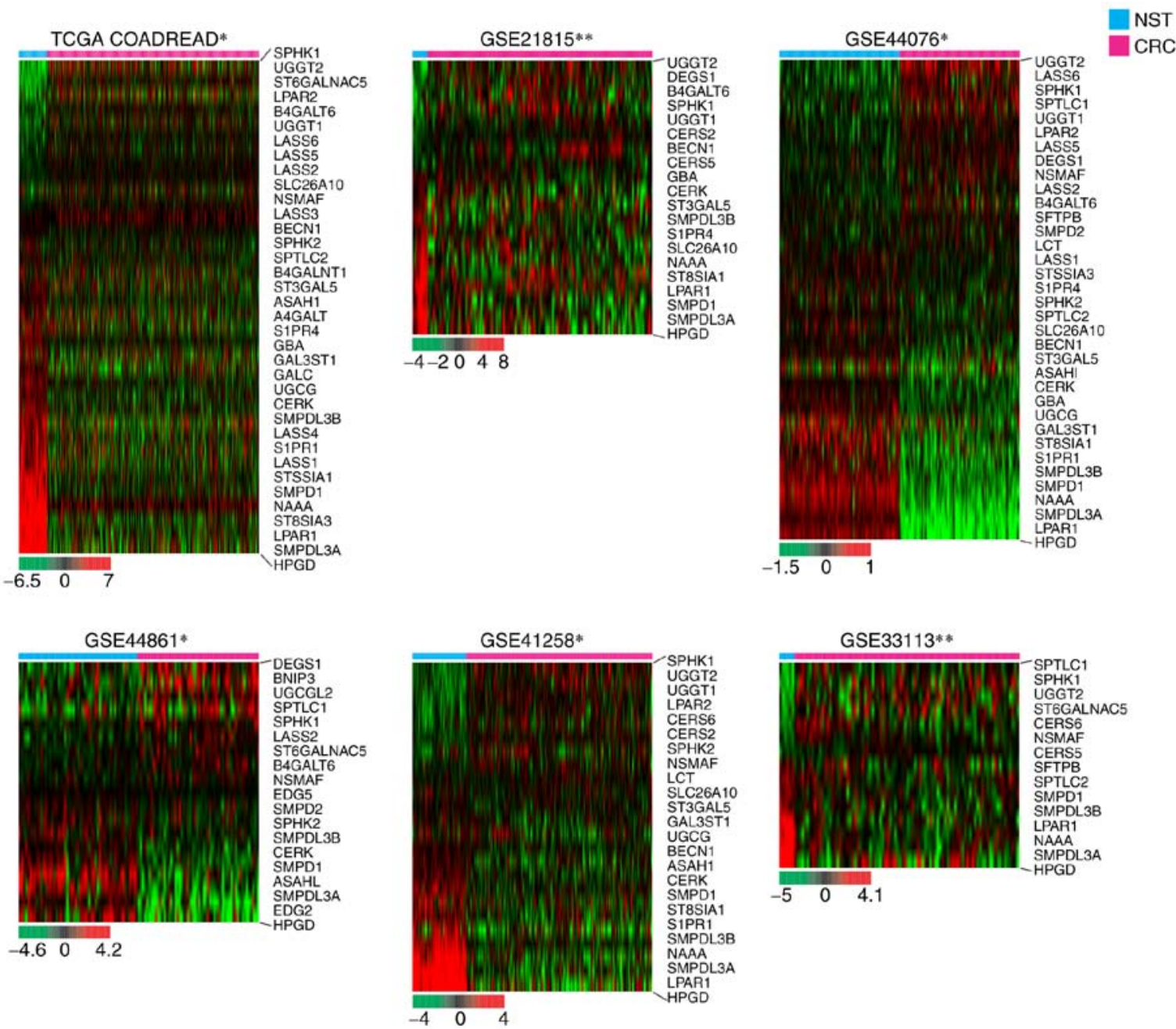

Figure 2. Heat-map showing significant differential expression of the sphingolipid metabolism-related genes in CRC tissues compared with NST of 6 independent CRC cohorts. The data are presented in matrix format in which rows represent individual genes and columns represent each tissue. Each cell in the matrix represents the expression level of a gene feature in an individual tissue. Expression levels have been standardized (centered and scaled) within columns for visualization. The red and green color in cells reflect relative high and low expression levels, respectively, as indicated by the scale bar. Images were obtained by re-analysis of the raw data of the respective cohort. Samples were sorted from left to right in the order of NSTs and CRC tissues according to the standardized expression level of each gene as indicated. "Student's t-test and ${ }^{* *}$ Mann Whitney U test; $\mathrm{P}<0.05$. CRC, colorectal cancer; NST, non-neoplastic surrounding colon tissues; TCGA-COADREAD, The Cancer Genome Atlas Colon and Rectal Cancer.

with CRC (Fig. 1). To identify the significance of altered mRNA expression levels between CRC and NST, Student's t-test or Mann Whitney $U$ test were performed $(\mathrm{P}<0.05)$. As demonstrated in Fig. 2, hierarchical clustering revealed that various sphingolipid metabolism-related genes were significantly dysregulated in CRC tissues compared with NST from the same patient groups. The list of analyzed sphingolipid metabolism-related genes is presented in Table II. Sphingosine kinase 1 (SPHKI) and UDP-glucose glycoprotein glucosyltransferase 2 (UGGT2) were significantly upregulated in the CRC tissues of all cohorts, while 15-hydroxyprostaglandin dehydrogenase $(H P G D)$, lysophosphatidic acid receptor 1 (LPARI), N-acylethanolamine acid amidase (NAAA), sphingomyelin phosphodiesterase $1(S M P D 1)$ and sphingomyel in phosphodiesterase acid-like 3A (SMPDL3A) were significantly downregulated in the CRC tissues of all cohorts (Fig. 2 and Table II).

Dysregulation of various CerSs in six independent CRC cohorts. Next, the present study evaluated whether the mRNA expression levels of the four CerS genes, which are abundant in colorectal tissues (30), are dysregulated in human CRC specimens with respect to NST. As demonstrated in Fig. 3, among six cohorts, CERS2 mRNA levels were significantly increased in five independent cohorts, while CERS5 and CERS6 were significantly upregulated in four independent cohorts. The specific platforms of each cohort and their associated studies are listed in Table III.

Altered CerS genes mRNA expression in Korean patients with $C R C$. To determine whether there is altered CERS2, CERS4, CERS5 and/or CERS6 mRNA expression in Korean patients with CRC, the expression levels of these four CerSs were measured using qPCR in 59 paired CRC and NST specimens from Korean patients. Following exclusion of unqualified results, the qPCR data were analyzed. The present study revealed that mRNA expression levels of all four CerS genes were significantly upregulated in CRC tissues compared with corresponding NSTs $(C E R S 2, \mathrm{P}<0.001 ; C E R S 4, \mathrm{P}=0.006$; CERS5, $\mathrm{P}<0.001$; CERS6, $\mathrm{P}<0.001$; Fig. 4; Table IV). 
Table II. List of the analyzed genes involved in sphingolipid metabolism (Student's t-test, Mann Whitney $\mathrm{U}$ test; P<0.05).

\begin{tabular}{|c|c|c|c|c|c|c|}
\hline Dataset & TCGA-COADREAD & GSE21815 b & GSE44076a & GSE44861 ${ }^{\mathrm{a}}$ & GSE41258 & GSE33113 $3^{\mathrm{b}}$ \\
\hline No. analyzed genes & 36 & 20 & 35 & 19 & 24 & 15 \\
\hline \multirow[t]{36}{*}{ Gene symbol } & A4GALT & B4GALT6 & ASAH1 & ASAHL (NAAA) & ASAH1 & CERS5 \\
\hline & ASAH1 & BECN1 & B4GALT6 & B4GALT6 & BECN1 & CERS6 \\
\hline & B4GALNT1 & CERK & BECN1 & BNIP3 & CERK & HPGD \\
\hline & B4GALT6 & CERS2 & CERK & CERK & CERS2 & LPAR1 \\
\hline & BECN1 & CERS5 & DEGS1 & DEGS1 & CERS6 & NAAA \\
\hline & CERK & DEGS1 & GAL3ST1 & EDG2 (LPAR1) & GAL3ST1 & NSMAF \\
\hline & GAL3ST1 & GBA & GBA & EDG5 (S1PR2) & HPGD & SFTPB \\
\hline & GALC & HPGD & HPGD & HPGD & LCT & SMPD1 \\
\hline & GBA & LPAR1 & LASS1 & CERS2 & LPAR1 & SMPDL3A \\
\hline & HPGD & NAAA & LASS2 & NSMAF & LPAR2 & SMPDL3B \\
\hline & LASS1 & S1PR4 & LASS5 & SMPD1 & NAAA & SPHK1 \\
\hline & LASS2 & SLC26A10 & LASS6 & SMPD2 & NSMAF & SPTLC1 \\
\hline & LASS3 & SMPD1 & LCT & SMPDL3A & S1PR1 & SPTLC2 \\
\hline & LASS4 & SMPDL3A & LPAR1 & SMPDL3B & SLC26A10 & ST6GALNAC5 \\
\hline & LASS5 & SMPDL3B & LPAR2 & SPHK1 & SMPD1 & UGGT2 \\
\hline & LASS6 & SPHK1 & NAAA & SPHK2 & SMPDL3A & \\
\hline & LPAR1 & ST3GAL5 & NSMAF & SPTLC1 & SMPDL3B & \\
\hline & LPAR2 & ST8SIA1 & S1PR1 & ST6GALNAC5 & SPHK1 & \\
\hline & NAAA & UGGT1 & S1PR4 & UGCGL2 (UGGT2) & SPHK2 & \\
\hline & NSMAF & UGGT2 & SFTPB & & ST3GAL5 & \\
\hline & S1PR1 & & SLC26A10 & & ST8SIA1 & \\
\hline & S1PR4 & & SMPD1 & & UGCG & \\
\hline & SLC26A10 & & SMPD2 & & UGGT1 & \\
\hline & SMPD1 & & SMPDL3A & & UGGT2 & \\
\hline & SMPDL3A & & SMPDL3B & & & \\
\hline & SMPLL3B & & SPHK1 & & & \\
\hline & SPHK1 & & SPHK2 & & & \\
\hline & SPHK2 & & SPTLC1 & & & \\
\hline & SPTLC2 & & SPTLC2 & & & \\
\hline & ST3GAL5 & & ST3GAL5 & & & \\
\hline & ST6GALNAC5 & & ST8SIA1 & & & \\
\hline & ST8SIA1 & & ST8SIA3 & & & \\
\hline & ST8SIA3 & & UGCG & & & \\
\hline & UGCG & & UGGT1 & & & \\
\hline & UGGT1 & & UGGT2 & & & \\
\hline & UGGT2 & & & & & \\
\hline
\end{tabular}

${ }^{a}$ Student's t-test, ${ }^{b}$ Mann Whitney U test. TCGA-COADREAD, The Cancer Genome Atlas Colon and Rectal Cancer.

Table III. mRNA expression levels of CerS gene in colorectal cancer tissues of patients from various datasets used in the present study.

\begin{tabular}{|c|c|c|c|c|c|c|}
\hline Dataset & Platform & CERS2 & CERS4 & CERS5 & CERS6 & (Refs.) \\
\hline TCGA (COADREAD) & RNA sequencing & Up & Down & Up & Up & $(19)$ \\
\hline GSE21815 & Human Whole Genome Microarray 4x4K G4112F & $\mathrm{Up}$ & $\mathrm{N} / \mathrm{A}$ & Up & $\mathrm{N} / \mathrm{A}$ & $(20)$ \\
\hline GSE44076 & Affymetrix Human Genome U219 Array & Up & N/A & Up & Up & $(21)$ \\
\hline GSE44861 & Affymetrix HT Human Genome U133A Array & Up & N/A & N/A & N/A & $(22)$ \\
\hline GSE41258 & Affymetrix U133A Array & Up & N/A & N/A & Up & $(23)$ \\
\hline GSE33113 & Affymetrix Human Genome U133 Plus 2.0 Array & N/A & N/A & Up & Up & $(24)$ \\
\hline
\end{tabular}

CERS, ceramide synthase; TCGA-COADREAD, The Cancer Genome Atlas Colon and Rectal Cancer. 
Table IV. mRNA expression levels of CerS gene in CRC tissues as compared with NST of Korean patients with CRC.

\begin{tabular}{|c|c|c|c|c|c|c|c|c|c|c|}
\hline \multicolumn{2}{|l|}{ CERS family } & \multicolumn{2}{|l|}{ CERS2 } & \multicolumn{2}{|c|}{ CERS4 } & \multicolumn{2}{|c|}{ CERS5 } & \multicolumn{3}{|c|}{ CERS6 } \\
\hline No. patients & & 59 & & & & & & & 55 & \\
\hline Type of tissue & NST & & $\mathrm{CRC}$ & NST & $\mathrm{CRC}$ & NST & $\mathrm{CRC}$ & NST & & $\mathrm{CRC}$ \\
\hline Mean ( $\Delta \mathrm{Cq}$ value) & 5.85 & & 4.26 & 5.68 & 4.43 & 8.89 & 7.85 & 7.26 & & 4.51 \\
\hline Regulation & & $\mathrm{Up}$ & & & & & & & $\mathrm{Up}$ & \\
\hline P-value & & $<0.001$ & & & & & & & $<0.001$ & \\
\hline
\end{tabular}

Student t-test. CERS, ceramide synthase; NST, non-neoplastic surrounding colon tissues; CRC, colorectal cancer.

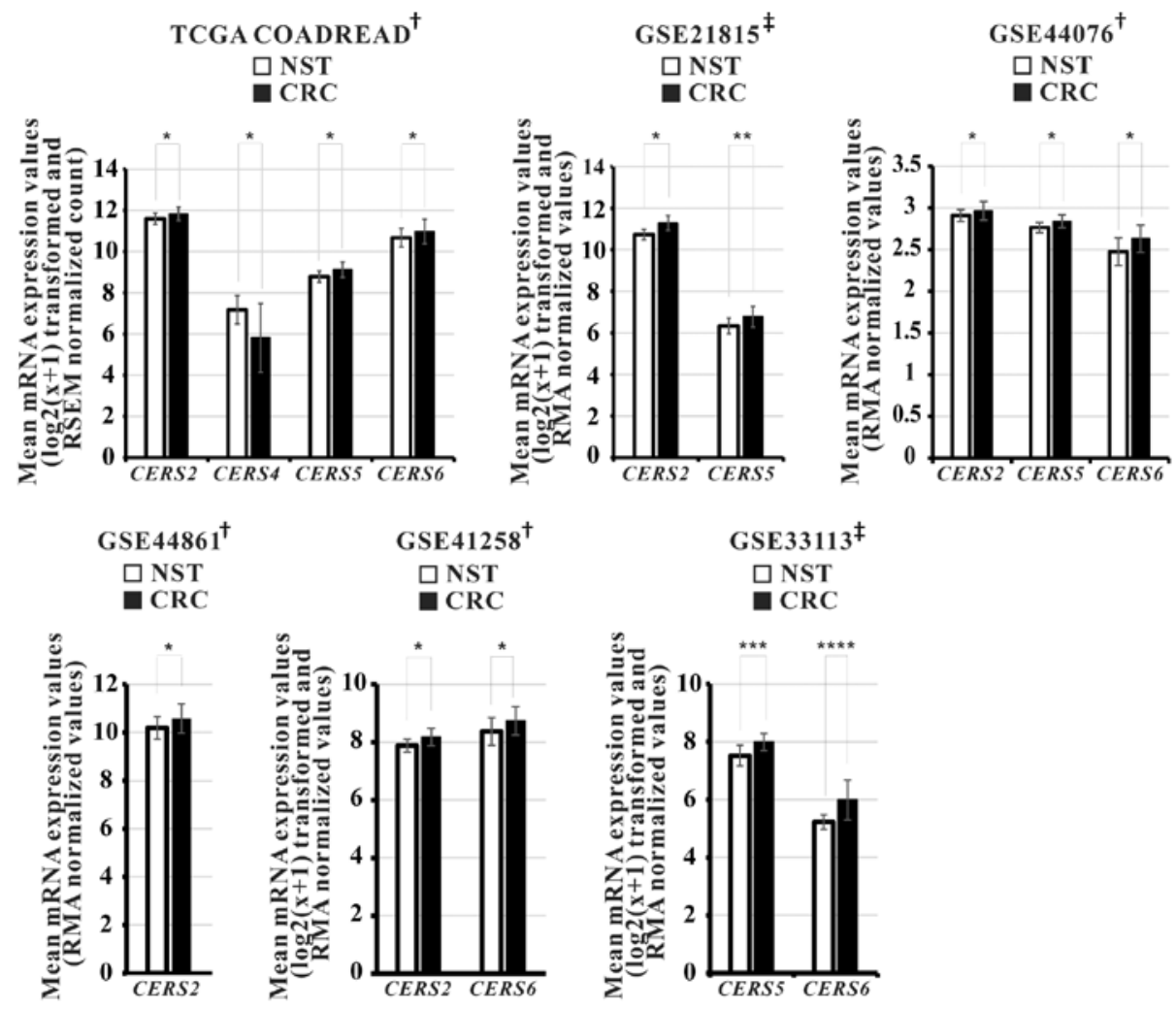

Figure 3. Relative mRNA expression levels of various ceramide synthases in the 6 independent CRC cohorts. Gene expression profiling datasets TCGA-COADREAD (NST, n=51; CRC, n=380), GSE21815 (NST, n=9; CRC, n=132), GSE44076 (NST, n=98; CRC, n=98), GSE44861 (NST, n=55; CRC, $\mathrm{n}=56$ ), GSE41258 (NST, n=54; CRC, $\mathrm{n}=186$ ) and GSE33113 (NST, n=6; CRC, n=90). P-values were calculated using ${ }^{\dagger}$ Student's t-test and ${ }^{\ddagger}$ Mann Whitney $\mathrm{U}$ test, ${ }^{*} \mathrm{P}<0.001,{ }^{* *} \mathrm{P}=0.005,{ }^{* * * *} \mathrm{P}=0.002,{ }^{* * * * *} \mathrm{P}=0.006$. CRC, colorectal cancer; NST, non-neoplastic surrounding colon tissues; TCGA-COADREAD, The Cancer Genome Atlas Colon and Rectal Cancer.

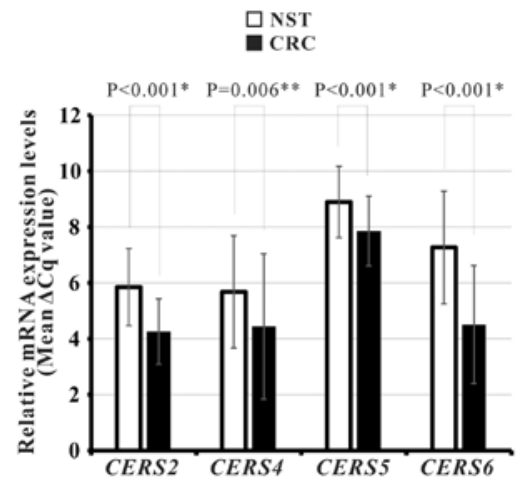

Figure 4. Relative mRNA expression levels of various ceramide synthases in CRC tissues and their corresponding NST of Korean patients. "Student's $\mathrm{t}$-test. The graph is representative of three independent experiments. CRC, colorectal cancer; NST, non-neoplastic surrounding colon tissues; TCGA-COADREAD, The Cancer Genome Atlas Colon and Rectal Cancer.
Exogenous CERS2 and CERS6 expression decreases the viability of human CRC cells. It has previously been observed that $C E R S 6$-overexpression reduces the proliferation of CRC cells and induces apoptosis, whereas CERS2-overexpression increases the proliferation of CRC cells (18). To confirm the effect of overexpressing CerSs in CRC cells, HCT116, HT29, SW403 and SW480 cells were transiently transfected with constructs to overexpress HA-CERS2 and HA-CERS6, respectively. After 48 and $72 \mathrm{~h}$, the numbers of viable cells were counted using a hemocytometer. As demonstrated in Fig. 5, overexpression of CERS2 and CERS6 decreased the viability of this panel of $C R C$ cell lines.

Inter-individual associations between mRNA expression levels of CerS genes in patients with CRC. Combinational 

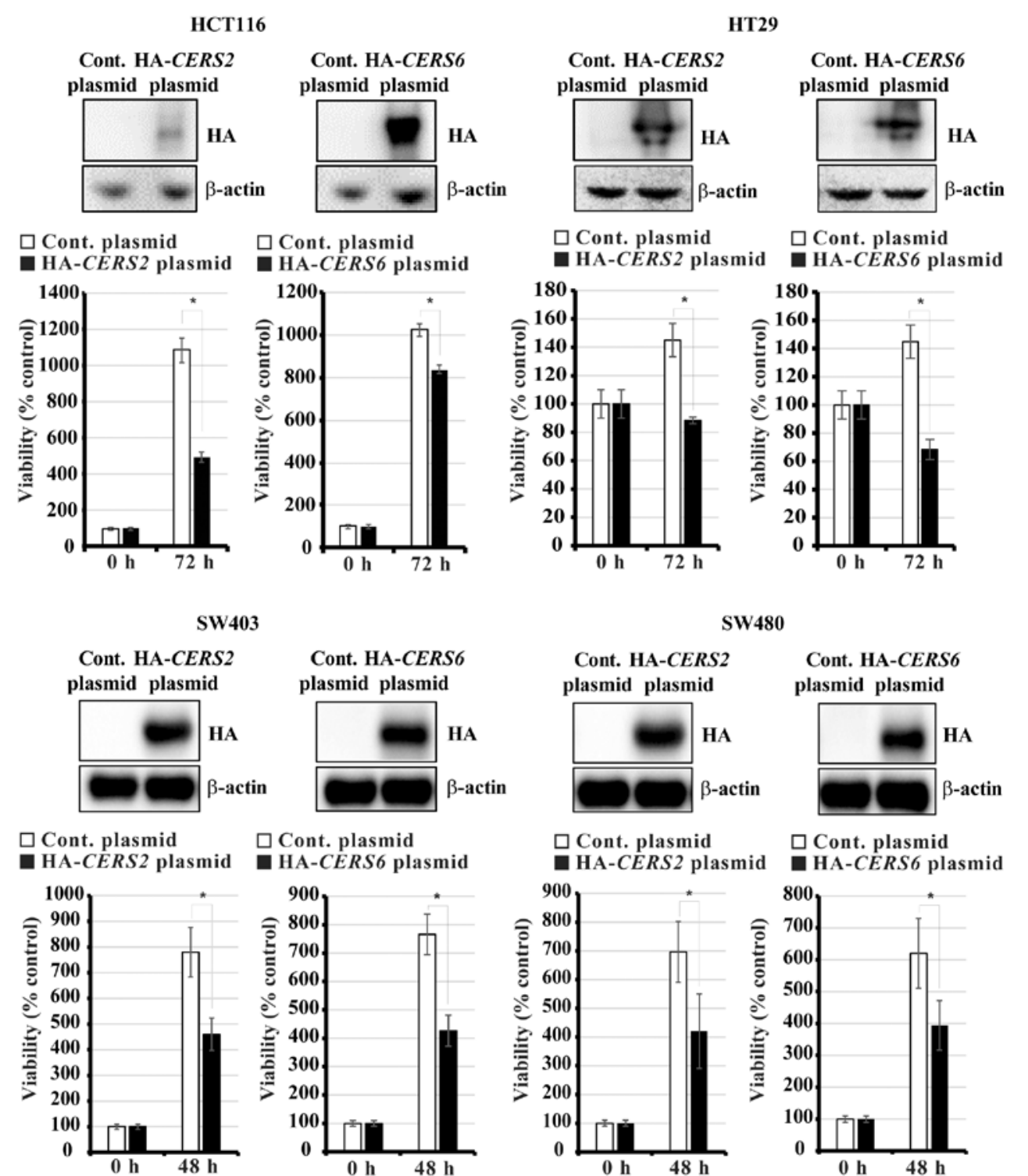

plasmid plasmid
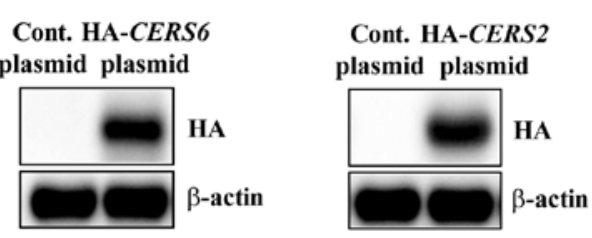

Cont. HA-CERS6

plasmid plasmid
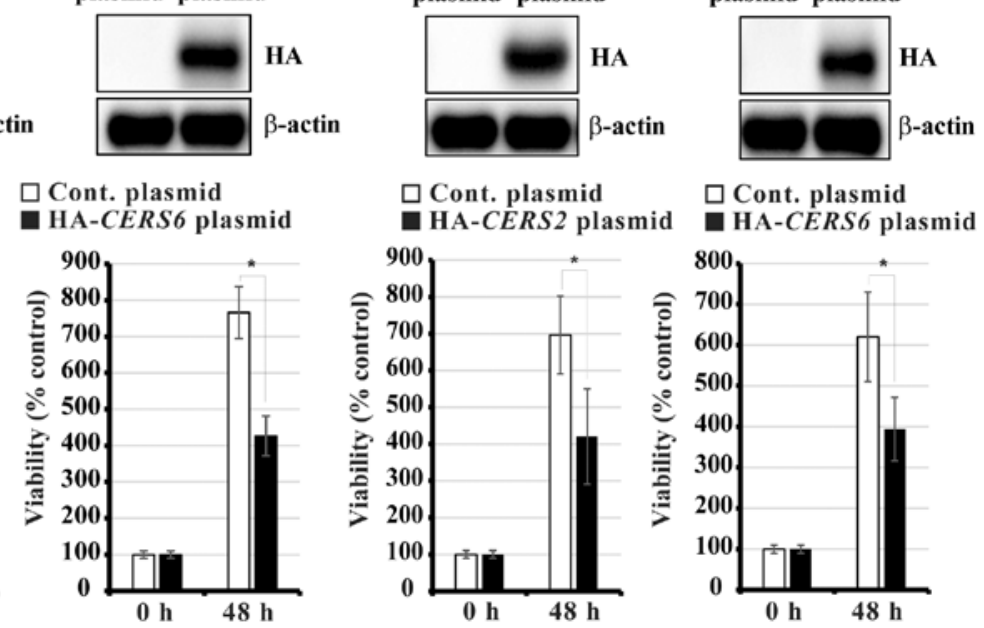

Figure 5. Effect of CERS2- or CERS6-overexpression on the viability of various colorectal cancer cell lines. HCT116, HT29, SW403 and SW480 cells were transiently transfected with control, HA-CERS2 and HA-CERS6 DNA constructs. At $24 \mathrm{~h}$ after transfection, cells were harvested and analyzed by western blot analysis with HA and $\beta$-actin antibodies. $\beta$-actin was used as a protein loading control. The viability of the cells were counted using a hemocytometer. Data are the mean values of three independent experiments and bars represent standard deviations. "P<0.05. CERS, ceramide synthase; Cont., control.

patterns of CerS gene expression, including CerS hetero-complexes and co-expression of CerS genes, serve important roles in sphingolipid metabolism $(31,32)$. Therefore, associations between the mRNA levels of each CerS gene were identified in the TCGA-COADREAD cohort and in the Korean CRC cohort. Using cBioPortal to analyze the TCGA-COADREAD cohort, co-expression analysis revealed that CERS4 and CERS5 had high correlation coefficients (Pearson's correlation $=0.36$; Spearman's correlation=0.48; Fig. 6A). Next, these correlations were assessed using Pearson's correlation coefficient analysis in the 59 Korean patients with CRC. There were significant correlations between CERS2 and CERS4, and also between CERS5 and CERS6, with a Pearson's correlation coefficient value of 0.532 ( $\mathrm{P}<0.001$; Fig. 6B) and 0.439 ( $\mathrm{P}=0.003$; Fig. 6C), respectively. Furthermore, significant correlations between the mRNA expression levels of CERS2 and CERS4 $(\mathrm{P}=0.009)$ and of CERS5 and CERS6 $(\mathrm{P}<0.001)$ were identified using Fisher's exact test (Table V).

Association between mRNA expression levels of CerS genes and clinicopathological parameters of Korean patients with $C R C$. To determine the clinicopathological implications of dysregulated expression of specific CerS genes in CRC, the association between CerS gene mRNA level and clinicopathological characteristics, which are used to represent progression and aggressiveness, were evaluated. Prior to the statistical analysis, the 44 patients, whose clinical data were available, were classified according to each clinicopathological characteristic (Table V). The results obtained from the statistical analysis of the Korean cohort revealed that altered mRNA expression levels of CerS genes were not significantly associated with any clinical parameters, including sex, age, Tumor-Node-Metastasis stage, body mass index or carcinoembryonic antigen titer. 
Table V. Association between mRNA expression levels of various CerS genes and clinicopathological parameters in Korean patients with colorectal cancer.

\begin{tabular}{|c|c|c|c|c|c|c|c|c|c|c|c|c|}
\hline \multirow[b]{2}{*}{ Parameter } & \multicolumn{3}{|c|}{ CERS2 expression } & \multicolumn{3}{|c|}{ CERS4 expression } & \multicolumn{3}{|c|}{ CERS5 expression } & \multicolumn{3}{|c|}{ CERS6 expression } \\
\hline & Low & High & P-value & Low & High & P-value & Low & High & P-value & Low & High & P-value \\
\hline Sex & & & $1.000^{\mathrm{b}}$ & & & $0.195^{\mathrm{b}}$ & & & $0.719^{b}$ & & & $1.000^{\mathrm{b}}$ \\
\hline Male & 24 & 4 & & 17 & 11 & & 20 & 8 & & 22 & 6 & \\
\hline Female & 14 & 2 & & 13 & 3 & & 13 & 3 & & 13 & 3 & \\
\hline Age, years & & & $0.606^{\mathrm{b}}$ & & & $1.000^{\mathrm{b}}$ & & & $0.408^{\mathrm{b}}$ & & & $0.659^{\mathrm{b}}$ \\
\hline$\leq 50$ & 8 & 2 & & 7 & & 3 & 9 & 1 & & 9 & 1 & \\
\hline$>50$ & 30 & 4 & & 23 & 11 & & 24 & 10 & & 26 & 8 & \\
\hline T stage & & & $0.609^{c}$ & & & $0.675^{\mathrm{c}}$ & & & $0.457^{\mathrm{c}}$ & & & $0.140^{\mathrm{c}}$ \\
\hline $\mathrm{T} 1$ & 2 & 0 & & 2 & 0 & & 0 & 2 & & 0 & 2 & \\
\hline $\mathrm{T} 2$ & 7 & 1 & & 4 & 4 & & 8 & 0 & & 7 & 1 & \\
\hline $\mathrm{T} 3$ & 24 & 4 & & 21 & 7 & & 20 & 8 & & 23 & 5 & \\
\hline $\mathrm{T} 4$ & 5 & 1 & & 3 & 3 & & 5 & 1 & & 5 & 1 & \\
\hline $\mathrm{N}$ stage & & & $0.063^{c}$ & & & $0.061^{\mathrm{c}}$ & & & $0.055^{\mathrm{c}}$ & & & $0.288^{c}$ \\
\hline N0 & 25 & 2 & & 21 & 6 & & 18 & 9 & & 21 & 6 & \\
\hline N1 & 7 & 1 & & 5 & 3 & & 6 & 2 & & 5 & 3 & \\
\hline $\mathrm{N} 2$ & 6 & 3 & & 4 & 5 & & 9 & 0 & & 9 & 0 & \\
\hline N3 & 0 & 0 & & 0 & 0 & & 0 & 0 & & 0 & 0 & \\
\hline M stage & & & $0.456^{\mathrm{b}}$ & & & $0.581^{\mathrm{b}}$ & & & $0.558^{\mathrm{b}}$ & & & $0.566^{\mathrm{b}}$ \\
\hline Negative & 35 & 5 & & 28 & 12 & & 29 & 11 & & 31 & 9 & \\
\hline Positive & 3 & 1 & & 2 & 2 & & 4 & 0 & & 4 & 0 & \\
\hline BMI & & & $0.653^{c}$ & & & $0.320^{c}$ & & & $0.593^{c}$ & & & $0.566^{c}$ \\
\hline$\leq 18.5$ & 0 & 0 & & 0 & 0 & & 0 & 0 & & 0 & 0 & \\
\hline $18.5-24.9$ & 1 & 0 & & 1 & 0 & & 1 & 0 & & 1 & 0 & \\
\hline $25-29.9$ & 27 & 4 & & 19 & 12 & & 22 & 9 & & 25 & 6 & \\
\hline$>30$ & 10 & 2 & & 10 & 2 & & 10 & 2 & & 9 & 3 & \\
\hline CEA & & & $1.000^{\mathrm{b}}$ & & & $0.540^{\mathrm{a}}$ & & & $0.706^{\mathrm{b}}$ & & & $0.703^{b}$ \\
\hline$>5$ & 11 & 2 & & 8 & 5 & & 9 & 4 & & 11 & 2 & \\
\hline$\leq 5$ & 27 & 4 & & 22 & 9 & & 24 & 7 & & 24 & 7 & \\
\hline CERS2 & & & & & & $0.009^{\mathrm{b}}$ & & & $0.630^{\mathrm{b}}$ & & & $1.000^{\mathrm{b}}$ \\
\hline Low & & & & 29 & 9 & & 29 & 9 & & 30 & 8 & \\
\hline High & & & & 1 & 5 & & 4 & 2 & & 5 & 1 & \\
\hline CERS4 & & & $0.009^{\mathrm{b}}$ & & & & & & $0.456^{\mathrm{b}}$ & & & $0.233^{b}$ \\
\hline Low & 29 & 1 & & & & & 21 & 9 & & 22 & 8 & \\
\hline High & 9 & 5 & & & & & 12 & 2 & & 13 & 1 & \\
\hline CERS5 & & & $0.630^{\mathrm{b}}$ & & & $0.456^{\mathrm{b}}$ & & & & & & $<0.001^{\mathrm{b}}$ \\
\hline Low & 29 & 4 & & 21 & 12 & & & & & 31 & 2 & \\
\hline High & 9 & 2 & & 9 & 2 & & & & & 4 & 7 & \\
\hline CERS6 & & & $1.000^{\mathrm{b}}$ & & & $0.233^{\mathrm{b}}$ & & & $<0.001^{\mathrm{b}}$ & & & \\
\hline Low & 30 & 5 & & 22 & 13 & & 31 & 4 & & & & \\
\hline High & 8 & 1 & & 8 & 1 & & 2 & 7 & & & & \\
\hline
\end{tabular}

aPearson's $\chi^{2}$ test; ${ }^{b}$ Fisher's exact test; ${ }^{\mathrm{c} L i n e a r}$ by linear association. CERS, ceramide synthase; BMI, body mass index; CEA, carcinoembryonic antigen. 
A

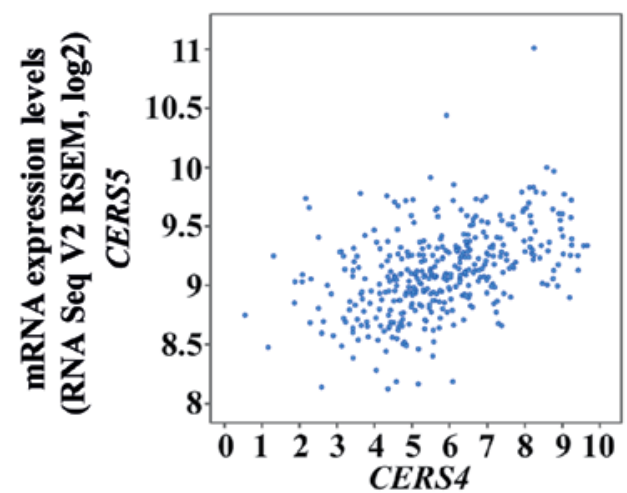

B

C
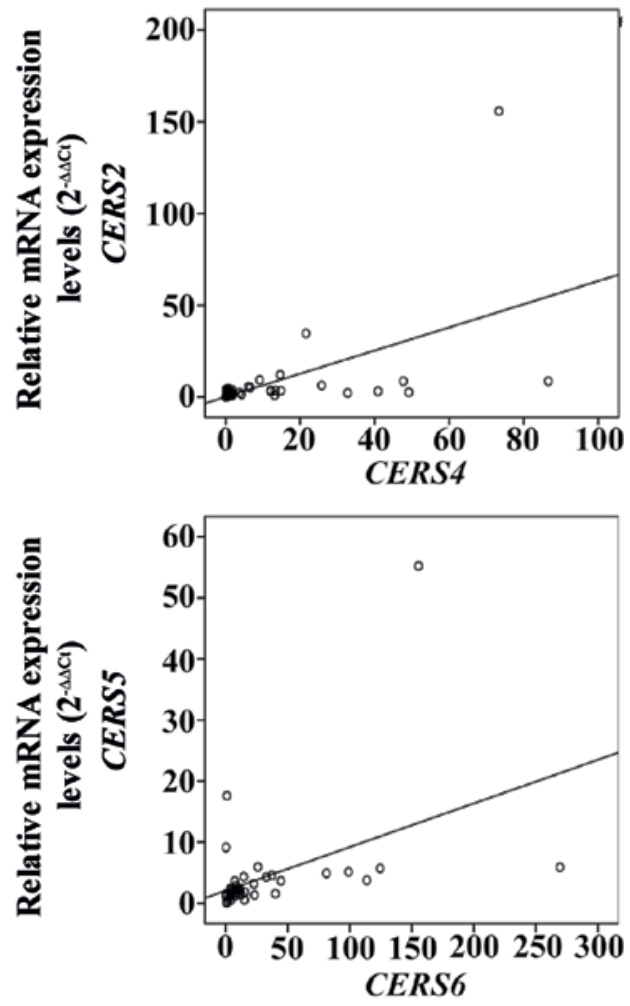

Figure 6. Correlation between mRNA expression levels of inter-individual CerS in the TCGA-COADREAD cohort and in the cohort of Korean patients with CRC. (A) CERS4 and CERS5 in the TCGA-COADREAD cohort. (B) CERS2 and CERS4 in the cohort of Korean patients with CRC. (C) CERS5 and CERS6 in the cohort of Korean patients with CRC. CERS, ceramide synthase; TCGA-COADREAD, The Cancer Genome Atlas Colon and Rectal Cancer; CRC, colorectal cancer.

\section{Discussion}

Sphingolipid metabolism serves a critical role in mammalian cell growth arrest and survival (33). Accumulating evidence have demonstrated that CerS, a major component in sphingolipid metabolism (7), regulates various biological phenomenon, including apoptosis (34), cancer (17,35), ER stress (36), hepatopathy (37), hypoxia/re-oxygenation injury (38), lipid metabolism (39), neurodegeneration (40), and sensitivity to chemotherapeutic drugs and radiation (30). Although aberrant CerS expression is correlated with cell death and proliferation (10-14) in various types of cancer, much uncertainty remains regarding the dysregulated mRNA levels of CerS gene in CRC and the clinical implications of this.
The aims of the present study were to investigate the mRNA expression levels and functions of CerS genes, which are primarily expressed in the intestine $(30,41)$, and analyze their clinicopathological implications in patients with CRC. To begin with, significantly dysregulated sphingolipid metabolism-related genes were identified in the heat-maps of 6 independent CRC cohorts (Fig. 2). The hierarchical clustering results demonstrated considerable dysregulation of sphingolipid metabolism-related genes in CRC tissues compared with corresponding NST of independent CRC cohorts. Among the considerably altered genes, certain genes were overlapping over 6 independent cohorts. SPHK1 and UGGT2 were significantly upregulated in CRC tissues. This result is in accordance with those of recent studies that indicated that SPHK1 is overexpressed and serves an important role in tumorigenesis, proliferation, invasiveness and metastasis in CRC $(42,43)$. On the other hand, HPGD, LPAR1,NAAA, SMPDI and SMPDL3A were all significantly downregulated in CRC tissues. HPGD is a cytoplasmic enzyme responsible for degrading PGE2 in colorectal tissue (44), and functions as a tumor suppressor gene in various types of cancer (45-48). The present study observed that HPGD was downregulated in 6 independent CRC cohorts (Fig. 2). However, little is known regarding the cellular functions and clinicopathological implications of LPAR1, NAAA, SMPD1, SMPDL3A and UGGT2 in CRC. Therefore, further studies investigating the functional role of these genes in CRC are required as these transcripts may be diagnostic markers or promising therapeutic candidates.

Additionally, the differential mRNA levels of CERS2, CERS4, CERS5 and CERS6 in CRC and NST were analyzed in 1,001 patients with CRC from 6 independent publicly-available CRC cohorts and a cohort of Korean patients with CRC. The results of the present study should be interpreted with caution as qPCR, RNA-Seq and microarray are different experimental platforms with different sensitivities, principles and dynamic ranges. Nonetheless, the results revealed that CERS2 was significantly upregulated in the majority of cohorts (Fig. 3; Table III) and in the cohort of Korean patients with CRC (Fig. 4; Table IV). It was recently demonstrated that CERS2-overexpression had no effect on the viability of HCT116 cells, whereas overexpressing CERS2 plus the addition of very-long chain acyl-CoAs significantly enhanced colony formation in HCT116 cells (18). Unlike these previous results, the present study revealed that CERS2-overexpression reduced the viability of various human CRC cells, including HCT116 cells (Fig. 5). The primary technical differences between these two experiments are the culture time following transfection and the use of different expression plasmids. Additionally, knockdown experiments were performed using shRNAs against CERS 2 mRNA and CERS6 mRNA, knockdown of CerS2 or CerS6 did not affect the proliferation of CRC SW403 and SW480 cells (data not shown). Although the exact mechanism that underlies the effect on cell viability was not elucidated in the present study, it is possible that sustained cell culture time following transfection may affect the synthesis of ceramides of various chain lengths.

It has been reported that increased expression of CerS6 and C16:0-Ceramide resulted in a sensitization of SW620 cells to TRAIL-induced apoptosis (49), and CERS6-overexpression significantly inhibited the colony formation capacity and increased the apoptosis of HCT116 cells (18). In accordance 
with these previous results, the present study demonstrated that CERS6 is significantly upregulated in CRC tissues, compared with NST (Figs. 3 and 4; Table IV) and CERS6-overexpression led to inhibition of cell viability in various human CRC cells (Fig. 5). Notably, controversial results have demonstrated that CerS6 and C16:0-Ceramide protected cells against ER-stress in human head and neck squamous cell carcinomas (36). Although oncogenes are usually upregulated in cancer tissues compared with non-neoplastic tissues, previous studies and the results presented in the present study indicated that the roles of CerSs and ceramides of specific chain lengths are complicated and cell type-dependent. Notably, it was demonstrated that CERS4 was significantly upregulated, but only in the cohort of Korean patients with CRC (Fig. 4), while it was downregulated in the TCGA-COADREAD cohort (Fig. 3). Future studies specifically focused on CERS4 in different CRC populations are required in order to understand this phenomena.

Additionally, the present study evaluated correlations between inter-individual mRNA expression levels of CerS genes and their clinicopathological implications in patients with CRC. A recent study revealed that inter-individual differences in the mRNA expression levels of CerS genes are significantly correlated with each other in cancer tissues (17). Furthermore, Combinational patterns of CerS expression are involved in sphingolipid metabolism $(31,32)$. The results of analyzing correlations between inter-individual CerS genes mRNA expression levels revealed a correlation between CERS4 and CERS5 in TCGA-COADREAD, between CERS2 and CERS4, and between CERS5 and CERS6 in the cohort of Korean patients with CRC. However, combinational patterns of CerS expression may be associated with sphingolipid metabolism. Therefore, it will be important to determine which components serve critical roles in sphingolipid metabolism in different disease and tissue settings. To the best of our knowledge, the present study was the first to investigate the clinicopathological implications of dysregulated CerS genes mRNA expression in CRC. However, no correlation was observed between mRNA expression levels of specific CerS genes and the investigated clinicopathological parameters.

In conclusion, the present study revealed that the mRNA expression levels of CERS2, CERS4, CERS5 and CERS6 were significantly upregulated or downregulated in various independent CRC cohorts, suggesting that dysregulated CerS gene expression may serve a role in CRC development.

\section{Acknowledgements}

The authors would like to thank all members of their research group for providing enthusiastic participation in the present study. The biospecimens for the present study were provided by the Keimyung Human Bio-Resource Bank, a member of the National Biobank of Korea, which is supported by the Ministry of Health and Welfare. All samples derived from the National Biobank of Korea were obtained following receipt of written informed consent and Institutional Review Board approval.

\section{Funding}

The present study was supported by the National Research Foundation of Korea Grant funded by the Korean Government
(Ministry of Science, ICT \& Future Planning; grant nos. 2017R1C1B5016670 and 2014R1A5A2010008).

\section{Availability of data and materials}

The datasets used during the present study are available from the corresponding author upon reasonable request. The primary and processed data used to generate the analyses presented here can be downloaded by registered users from The Cancer Genome Atlas at http://tcga-data.nci.nih.gov/tcga/tcgaDownload.jsp.

\section{Authors' contributions}

SWJ, WJP and SK contributed to the conception and design of the study, analysis of the data, interpretation of results and the writing of the manuscript. SWJ, WJP, HM and SK contributed to the acquisition of data. SWJ, WJP, HM, SKB, $\mathrm{IH}$ and SK performed the experiments. TKK contributed to the conception and design of the study. JWP and IH contributed to the conception and design of the study and provided guidance regarding the clinical implications of the study. WJP and SK reviewed and edited the manuscript. All authors read and approved the manuscript, and agree to be accountable for all aspects of the research in ensuring that the accuracy or integrity of any part of the work are appropriately investigated and resolved.

\section{Ethics approval and consent to participate}

The experimental study was approved by the Institutional Review Board of Keimyung University Dongsan Medical Cent er (approval no. 2015-11-059-001). Written informed consent was obtained from each study participant.

\section{Patient consent for publication}

Not applicable.

\section{Competing interests}

The authors declare that they have no competing interest.

\section{References}

1. Torre LA, Bray F, Siegel RL, Ferlay J, Lortet-Tieulent J and Jemal A: Global cancer statistics, 2012. CA Cancer J Clin 65: 87-108, 2015

2. Edwards BK, Ward E, Kohler BA, Eheman C, Zauber AG, Anderson RN, Jemal A, Schymura MJ, Lansdorp-Vogelaar I, Seeff LC, et al: Annual report to the nation on the status of cancer, 1975-2006, featuring colorectal cancer trends and impact of interventions (risk factors, screening, and treatment) to reduce future rates. Cancer 116: 544-573, 2010.

3. Bosetti C, Levi F, Rosato V, Bertuccio P, Lucchini F, Negri E and La Vecchia C: Recent trends in colorectal cancer mortality in Europe. Int J Cancer 129: 180-191, 2011.

4. Fearon ER and Vogelstein B: A genetic model for colorectal tumorigenesis. Cell 61: 759-767, 1990.

5. Fearon ER: Molecular genetics of colorectal cancer. Ann Rev Pathol 6: 479-507, 2011.

6. Cuvillier O, Pirianov G, Kleuser B, Vanek PG, Coso OA, Gutkind S and Spiegel S: Suppression of ceramide-mediated programmed cell death by sphingosine-1-phosphate. Nature 381: 800-803, 1996 
7. Newton J, Lima S, Maceyka M and Spiegel S: Revisiting the sphingolipid rheostat: Evolving concepts in cancer therapy. Exp Cell Res 333: 195-200, 2015.

8. Morad SA and Cabot MC: Ceramide-orchestrated signalling in cancer cells. Nat Rev Cancer 13: 51-65, 2013.

9. Stiban J, Tidhar R and Futerman AH: Ceramide synthases: Roles in cell physiology and signaling. Adv Exp Med Biol 688: 60-71, 2010.

10. Fan SH, Wang YY, Lu J, Zheng YL, Wu DM, Zhang ZF, Shan Q, Hu B, Li MQ and Cheng W: CERS2 suppresses tumor cell invasion and is associated with decreased V-ATPase and MMP-2/MMP-9 activities in breast cancer. J Cell Biochem 116 502-513, 2015.

11. Chen J, Li X, Ma D, Liu T, Tian P and Wu C: Ceramide synthase- 4 orchestrates the cell proliferation and tumor growth of liver cancer in vitro and in vivo through the nuclear factor- $\mathrm{kB}$ signaling pathway. Oncol Lett 14: 1477-1483, 2017.

12. Suzuki M, Cao K, Kato S, Komizu Y, Mizutani N, Tanaka K, Arima C, Tai MC, Yanagisawa K, Togawa N, et al: Targeting ceramide synthase 6-dependent metastasis-prone phenotype in lung cancer cells. J Clin Invest 126: 254-265, 2016.

13. Edmond V, Dufour F, Poiroux G, Shoji K, Malleter M, Fouqué A, Tauzin S, Rimokh R, Sergent O, Penna A, et al: Downregulation of ceramide synthase- 6 during epithelial-to-mesenchymal transition reduces plasma membrane fluidity and cancer cell motility. Oncogene 34: 996-1005, 2015.

14. Fitzgerald S, Sheehan KM, Espina V, O'Grady A, Cummins R, Kenny D, Liotta L, O'Kennedy R, Kay EW and Kijanka GS: High CerS5 expression levels associate with reduced patient survival and transition from apoptotic to autophagy signalling pathways in colorectal cancer. J Pathol Clin Res 1: 54-65, 2015.

15. Separovic D, Breen P, Joseph N, Bielawski J, Pierce JS, VAN Buren E and Gudz TI: siRNA-mediated down-regulation of ceramide synthase 1 leads to apoptotic resistance in human head and neck squamous carcinoma cells after photodynamic therapy. Anticancer Res 32: 2479-2485, 2012.

16. Senkal CE, Ponnusamy S, Rossi MJ, Bialewski J, Sinha D, Jiang JC, Jazwinski SM, Hannun YA and Ogretmen B: Role of human longevity assurance gene 1 and $\mathrm{C}_{18}$-ceramide in chemotherapy-induced cell death in human head and neck squamous cell carcinomas. Mol Cancer Ther 6: 712-722, 2007.

17. Erez-Roman R, Pienik R and Futerman AH: Increased ceramide synthase 2 and 6 mRNA levels in breast cancer tissues and correlation with sphingosine kinase expression. Biochem Biophys Res Commun 391: 219-223, 2010.

18. Hartmann D, Lucks J, Fuchs S, Schiffmann S, Schreiber Y, Ferreirós N,Merkens J,Marschalek R, Geisslinger G and GröschS: Long chain ceramides and very long chain ceramides have opposite effects on human breast and colon cancer cell growth. Int J Biochem Cell Biol 44: 620-628, 2012.

19. Cancer Genome Atlas Network: Comprehensive molecular characterization of human colon and rectal cancer. Nature 487 330-337, 2012

20. Kogo R, Shimamura T, Mimori K, Kawahara K, Imoto S, Sudo T, Tanaka F, Shibata K, Suzuki A, Komune S, et al: Long noncoding RNA HOTAIR regulates polycomb-dependent chromatin modification and is associated with poor prognosis in colorectal cancers. Cancer Res 71: 6320-6326, 2011.

21. Sanz-Pamplona R, Berenguer A, Cordero D, Molleví DG, Crous-Bou M, Sole X, Paré-Brunet L, Guino E, Salazar R, Santos C, et al: Aberrant gene expression in mucosa adjacent to tumor reveals a molecular crosstalk in colon cancer. Mol Cancer 13: 46, 2014

22. Ryan BM, Zanetti KA, Robles AI, Schetter AJ, Goodman J, Hayes RB, Huang WY, Gunter MJ, Yeager M, Burdette L, et al: Germline variation in NCF4, an innate immunity gene, is associated with an increased risk of colorectal cancer. Int J Cancer 134: 1399-1407, 2014

23. Sheffer M, Bacolod MD, Zuk O, Giardina SF, Pincas H, Barany F, Paty PB, Gerald WL, Notterman DA and Domany E: Association of survival and disease progression with chromosomal instability: A genomic exploration of colorectal cancer. Proc Natl Acad Sci USA 106: 7131-7136, 2009.

24. de Sousa E Melo F, Colak S, Buikhuisen J, Koster J, Cameron K, de Jong JH, Tuynman JB, Prasetyanti PR, Fessler E, van den Bergh SP, et al: Methylation of cancer-stem-cell-associated Wnt target genes predicts poor prognosis in colorectal cancer patients. Cell Stem Cell 9: 476-485, 2011
25. Irizarry RA, Hobbs B, Collin F, Beazer-Barclay YD, Antonellis KJ, Scherf U and Speed TP: Exploration, normalization, and summaries of high density oligonucleotide array probe level data. Biostatistics 4: 249-264, 2003.

26. Edge SB and Cancer AJCo: AJCC Cancer Staging Handbook: Form the AJCC Cancer Staging Manual. Springer, New York, 2010.

27. Schmittgen TD and Livak KJ: Analyzing real-time PCR data by the comparative C(T) method. Nat Protoc 3: 1101-1108, 2008

28. Cerami E, Gao J, Dogrusoz U, Gross BE, Sumer SO, Aksoy BA, Jacobsen A, Byrne CJ, Heuer ML, Larsson E, et al: The cBio cancer genomics portal: An open platform for exploring multidimensional cancer genomics data. Cancer Discov 2: 401-404, 2012.

29. Ruckhäberle E, Rody A, Engels K, Gaetje R, von Minckwitz G, Schiffmann S, Grösch S, Geisslinger G, Holtrich U, Karn T, et al: Microarray analysis of altered sphingolipid metabolism reveals prognostic significance of sphingosine kinase 1 in breast cancer. Breast Cancer Res Treat 112: 41-52, 2008.

30. Mullen TD, Hannun YA and Obeid LM: Ceramide synthases at the centre of sphingolipid metabolism and biology. Biochem $\mathrm{J}$ 441: 789-802, 2012.

31. Park JW, Park WJ and Futerman AH: Ceramide synthases as potential targets for therapeutic intervention in human diseases. Biochim Biophys Acta 1841: 671-681, 2014

32. Mesicek J,Lee H,Feldman T, Jiang X, Skobeleva A, Berdyshev EV, Haimovitz-Friedman A, Fuks Z and Kolesnick R: Ceramide synthases 2,5 , and 6 confer distinct roles in radiation-induced apoptosis in HeLa cells. Cell Signal 22: 1300-1307, 2010.

33. Mandala SM, Thornton R, Tu Z, Kurtz MB, Nickels J, Broach J, Menzeleev R and Spiegel S: Sphingoid base 1-phosphate phosphatase: A key regulator of sphingolipid metabolism and stress response. Proc Natl Acad Sci USA 95: 150-155, 1998.

34. Panjarian S, Kozhaya L, Arayssi S, Yehia M, Bielawski J, Bielawska A, Usta J, Hannun YA, Obeid LM and Dbaibo GS: De novo $N$-palmitoylsphingosine synthesis is the major biochemical mechanism of ceramide accumulation following p53 up-regulation. Prostaglandins Other Lipid Mediat 86: 41-48, 2008.

35. Karahatay S, Thomas K, Koybasi S, Senkal CE, Elojeimy S, Liu X, Bielawski J, Day TA, Gillespie MB, Sinha D, et al: Clinical relevance of ceramide metabolism in the pathogenesis of human head and neck squamous cell carcinoma (HNSCC): Attenuation of $\mathrm{C}_{18}$-ceramide in HNSCC tumors correlates with lymphovascular invasion and nodal metastasis. Cancer Lett 256 : 101-111, 2007.

36. Senkal CE, Ponnusamy S, Bielawski J, Hannun YA and Ogretmen B: Antiapoptotic roles of ceramide-synthase-6-generated $\mathrm{C}_{16}$-ceramide via selective regulation of the ATF6/CHOP arm of ER-stress-response pathways. FASEB J 24: 296-308, 2010.

37. Pewzner-Jung Y, Brenner O, Braun S, Laviad EL, Ben-Dor S, Feldmesser E, Horn-Saban S, Amann-Zalcenstein D, Raanan C, Berkutzki T, et al: A critical role for ceramide synthase 2 in liver homeostasis: II. insights into molecular changes leading to hepatopathy. J Biol Chem 285: 10911-10923, 2010.

38. Jin J, Hou Q, Mullen TD, Zeidan YH, Bielawski J, Kraveka JM, Bielawska A, Obeid LM, Hannun YA and Hsu YT: Ceramide generated by sphingomyelin hydrolysis and the salvage pathway is involved in hypoxia/reoxygenation-induced Bax redistribution to mitochondria in NT-2 cells. J Biol Chem 283: 26509-26517, 2008.

39. Pewzner-Jung Y, Park H, Laviad EL, Silva LC, Lahiri S, Stiban J, Erez-Roman R, Brügger B, Sachsenheimer T, Wieland F, et al: A critical role for ceramide synthase 2 in liver homeostasis: I. alterations in lipid metabolic pathways. J Biol Chem 285: 10902-10910, 2010.

40. Spassieva SD, Ji X, Liu Y, Gable K, Bielawski J, Dunn TM, Bieberich E and Zhao L: Ectopic expression of ceramide synthase 2 in neurons suppresses neurodegeneration induced by ceramide synthase 1 deficiency. Proc Natl Acad Sci USA 113: 5928-5933, 2016.

41. Laviad EL, Albee L, Pankova-Kholmyansky I, Epstein S, Park H, Merrill AH Jr and Futerman AH: Characterization of ceramide synthase 2: Tissue distribution, substrate specificity, and inhibition by sphingosine 1-phosphate. J Biol Chem 283: 5677-5684, 2008.

42. Bao Y, Guo Y, Zhang C, Fan F and Yang W: Sphingosine kinase 1 and sphingosine-1-phosphate signaling in colorectal cancer. Int J Mol Sci 18: E2109, 2017. 
43. Long J, Xie Y, Yin J, Lu W and Fang S: SphK1 promotes tumor cell migration and invasion in colorectal cancer. Tumour Biol 37: 6831-6836, 2016.

44. Smartt HJ, Greenhough A, Ordóñez-Morán P, Talero E, Cherry CA, Wallam CA, Parry L, Al Kharusi M, Roberts HR, Mariadason JM, et al: $\beta$-catenin represses expression of the tumour suppressor 15-prostaglandin dehydrogenase in the normal intestinal epithelium and colorectal tumour cells. Gut 61 1306-1314, 2012.

45. Wolf I, O'Kelly J, Rubinek T, Tong M, Nguyen A, Lin BT, Tai HH, Karlan BY and Koeffler HP: 15-hydroxyprostaglandin dehydrogenase is a tumor suppressor of human breast cancer. Cancer Res 66: 7818-7823, 2006.

46. Ding Y, Tong M, Liu S, Moscow JA and Tai HH: NAD+-linked 15-hydroxyprostaglandin dehydrogenase (15-PGDH) behaves as a tumor suppressor in lung cancer. Carcinogenesis 26: 65-72, 2005.
47. Song HJ, Myung SJ, Kim IW, Jeong JY, Park YS, Lee SM, Nam WH, Ryu YM, Fink SP, Yang DH, et al: 15-hydroxyprostaglandin dehydrogenase is downregulated and exhibits tumor suppressor activity in gastric cancer. Cancer Invest 29: 257-265, 2011.

48. Myung SJ, Rerko RM, Yan M, Platzer P, Guda K, Dotson A, Lawrence E, Dannenberg AJ, Lovgren AK, Luo G, et al: 15-Hydroxyprostaglandin dehydrogenase is an in vivo suppressor of colon tumorigenesis. Proc Natl Acad Sci USA 103: 12098-12102, 2006.

49. White-Gilbertson S, Mullen T, Senkal C, Lu P, Ogretmen B, Obeid L and Voelkel-Johnson C: Ceramide synthase 6 modulates TRAIL sensitivity and nuclear translocation of active caspase-3 in colon cancer cells. Oncogene 28: 1132-1141, 2009. 